\title{
APLICAÇÃO DA FILOSOFIA SIX SIGMA PARA MELHORIA DA PERFORMANCE NUMA INDÚSTRIA DE EMBALAGENS METÁLICAS PARA BEBIDAS
}

\author{
David de Oliveira Costa (UCP) dcosta.doc@gmail.com \\ Marcos dos Santos (IME) marcosdossantos_doutorado_uff@yahoo.com.br \\ Daniel Augusto de Moura Pereira (UFCG) danielmoura@ufcg.edu.br
}

\section{Resumo}

Este estudo visa, diante da aplicação da filosofia Six Sigma e do método DMAIC, estruturar elementos científicos para garantir a estabilidade e maximizar a performance do processo de fabricação de tampas de alumínio. Entendendo que é necessário identificar e controlar as variáveis vitais do processo afim de evitar perdas relacionadas à produtividade pois, o impacto gerado por baixa performance afeta diretamente a saúde financeira do negócio, principalmente nesse cenário corporativo globalizado e de alta concorrência. Diante de elementos e métodos é possível identificar às origens de perdas na produtividade, bem como a relação entre a causa e seus efeitos, no processo produtivo.

Palavras-Chaves: DOE, DMAIC, Estabilidade, Melhoria contínua, Performance, Processos, Six Sigma, Teste de hipótese.

\section{Introdução}

Harry, Schoroeder (2000) entendem que os roteiros de melhoria são uma sequência estruturada de atividades a serem realizadas e ferramentas a serem aplicadas que visam produzir melhorias estruturadas nos diversos processos. Em síntese, seguindo esse guia ou, passo a passo, consegue-se ganhos e melhorias significativas nos processos em que estão submetidos, alcançando os objetivos desenhados pela direção. A filosofia Six Sigma nasceu e se desenvolveu em meados de 1980 na Motorola, nos Estados Unidos, porém a sua raiz originária já havia sido mencionada no livro Quality is Free, escrito por Philip Crosby, em 1979, onde uma das contribuições de Crosby para a gestão da qualidade foi o conceito do "zero defeito", que é a filosofia principal e essência do Six Sigma. Pode-se entender que, juntamente com o método DMAIC (acrônimo para expressar as etapas: Definir, Medir, Analisar, Implementar (melhorar) e Controlar), consolidou a base fundamental dos programas TQM (Total Quality Management), com foco na redução de variação dos processos. A filosofia Six Sigma evoluiu 
ao longo dos anos e atualmente é conhecido, por alguns especialistas, como Lean Six Sigma, para passar a ideia de melhoria de fluxo contínuo e redução da variação, já que esses seriam os focos dessas duas metodologias.

Rotondaro (2008) entende que, empresas globais utilizam e estruturam suas ações baseadas nessa metodologia e sistemática e, alcançam resultados diferenciados por amadurecerem essa filosofia em sua cultura organizacional. Já que o mercado atual exige uma diferenciação no potencial competitivo ou na estratégia competitiva, para sobressair dos demais. Para as empresas permanecerem nesse mercado altamente competitivo, o nível de exigência torna-se cada vez maior e isto está condicionado à globalização. Como forma de minimizar os impactos, a alternativa viável é aumentar a sua capacidade produtiva e à qualidade de processos e produtos. Werkema (2004) afirma que as empresas estão buscando estratégias que promovam melhorias em seus processos, visando reduzir custos e perdas durante o processo de fabricação, aumentando a qualidade de seus produtos com foco em aumentar a percepção de qualidade para o cliente. Neste contexto, na busca da performance global dos processos, as empresas estão adotando práticas reconhecidas no mercado bem como, metodologias científicas que promovam o contínuo aperfeiçoamento dos processos, com foco na entrega de valor agregado aos seus clientes. Portanto, este artigo tem como objetivo estruturar elementos científicos para garantir a estabilidade e maximizar a performance do processo de fabricação de tampas de alumínio.

\section{Fundamentação teórica}

\subsection{A filosofia Six Sigma}

Reduzir continuamente a variabilidade do processo é um dos pilares conceituais do Six Sigma e é desta maneira que visa eliminar possibilidade de falhas nos processos. E, consequentemente maximizar ganhos e estabilidade na qualidade. Atualmente, o Six Sigma é compreendido como uma prática de gestão, que busca melhorar a lucratividade de empresas de qualquer setor de atividade, independentemente do tamanho do negócio, com a finalidade de aumentar a participação de mercado, reduzir custos e otimizar as operações. Pyzdek, Keller (2011) entendem que a aplicação do Six Sigma ocorre com o apoio de uma série de ferramentas do Lean Manufacturing, para a identificação, análise e solução de problemas, com acentuado embasamento na coleta e tratamento de dados, e com suporte estatístico. A escala do nível 1 sigma que implicará, numa amostra de 1 milhão de peças, pelo menos 691.463 possibilidades 
de defeitos nessa população, conforme menciona a tabela abaixo, conforme a figura 1 . Um número extremamente alto e inaceitável nos tempos atuais, onde a alta concorrência do mercado atual e, não permite falhas.

Figura 1 - Tabela de relação do nível sigma com PPM

\begin{tabular}{ccc}
\hline Nível Sigma & Rendimento processo & PPM \\
\hline 1 & $30,90 \%$ & 691.462 \\
2 & $69,10 \%$ & 308.537 \\
3 & $93,30 \%$ & 66.807 \\
4 & $99,38 \%$ & 6.210 \\
5 & $99,98 \%$ & 233 \\
6 & $99,9997 \%$ & 3,4 \\
\hline
\end{tabular}

Fonte: Adaptado Pyzdek (2011)

Nesta situação, afirma-se que apenas 30,90\% do tempo, tal processo trabalha de forma efetiva e dentro dos padrões aceitáveis. Comparando com um processo com nível 6 Sigma, significa que apenas 3,4 defeitos a cada milhão produzidos e, é classificado como um processo de excelência ou, de qualidade de classe mundial. Um nível Six Sigma, representa 99,9997\% das oportunidades do processo, está sendo realizado dentro dos padrões, conforme ilustrado na tabela 1. Bornia (1995) afirma que cada nível sigma e sua respectiva relação com o índice de defeitos e conformidade do processo, justificando a relação direta entre nível de desperdício e margem de lucro.

\subsection{DMAIC: um método científico}

Esta metodologia evoluiu significativamente desde seu surgimento até os dias atuais e, essa evolução é contínua. O Six Sigma começou a ser aplicado em diversas empresas e diversos negócios e, mediante tal evolução, foi aumentando o número de ferramentas que a metodologia utiliza, sendo testados uma série de recursos, e hoje é possível compreender quais funcionam adequadamente. Rotondaro (2008) afirma que essa evolução natural também se deve a uma evolução tecnológica, pois hoje existem diversos softwares para análise de dados estatísticos. A filosofia Six Sigma, se aplicada ao planejamento estratégico é uma bússola direcionadora para o sistema de gestão, por ter elementos quantitativos e baseada em dados confiáveis em sua estrutura, o desdobramento de ações, por consequência, passa a ser orientada para resultados. 
Pyzdek, Keller (2011) entende que a metodologia DMAIC está fundamentada em três grandes objetivos, que são: redução de custos, otimização de produtos e processos e o aumento na percepção da qualidade do cliente.

\subsection{Performance como princípio de sobrevivência num cenário VUCA}

Certamente, que as incertezas sempre farão parte do ambiente corporativo, e que possivelmente, as soluções atuais não serão aplicáveis aos problemas do futuro. Mesmo que consigamos compreender as relações de causa e efeito de uma mudança, suas consequências são imprevisíveis. Diante de um cenário turbulento, competitivo, e dinâmico a performance será um pilar robusto para suportar essa estrutura nesse cenário. Um cenário conhecido, atualmente por VUCA (acrônimo volatilidade, incerteza, complexidade e ambiguidade) expressa a complexidade composta por fatores que são imprevisíveis em seus resultados, pois esses fatores fazem parte de um sistema complexo. Kotler, Keller (2016) entendem que a ambiguidade é essa falta de clareza dos impactos nesse novo cenário que pode dá margem à múltiplas interpretações igualmente pertinentes. Uma das estratégias para manter o equilíbrio a essa nova realidade, é aplicar projetos de melhorias para eliminar as perdas e equalizar seus custos. Nesse cenário de grande competitividade entre as organizações a performance, passa a ser uma necessidade e um diferencial competitivo pois, apenas garantir especificações e garantir requisitos não é mais suficiente nesse contexto.

Stamatis (2004) entende que, para garantir uma estratégia assertiva, dentre as diversas filosofias, metodologias, conceitos e ferramentas utilizadas como garantia de estabilidade e de padrões exigentes, o Six Sigma é a filosofia adequada que tem como base a metodologia DMAIC como ferramenta na obtenção de um modelo lógico e racional. Já que este, é um método científico, validado e reconhecido, no ambiente corporativo.

\subsection{OEE: estruturação da produtividade}

Simão \& Sami (2017) entendem que o conceito mais adequado para o OEE é: a consequência do desdobramento composto por estes três vetores: qualidade, produtividade e disponibilidade, que retratam, de forma completa, as condições de um ambiente corporativo e, diante do baixo desempenho, entender qual vetor foi a causa do evento. E dessa forma, pode-se aplicar técnicas específicas de tratativa da causa. O termo $O E E$ (Overall Equipment Effectiveness) que, para 
obtenção desse índice, o cálculo realizado será baseado no produto entre os vetores supracitados.

Exemplo:

Disponibilidade: um turno com 8 h de trabalho, com parada de 1 h para almoço. Durante a atividade, houve uma quebra no equipamento de $1 \mathrm{~h}$.

$\frac{6}{8}=\mathbf{0}, 75$

Qualidade: nesse turno, determinado equipamento produziu um total de 1.600 peças, sendo que desse total, 250 peças, estavam com falhas e foram rejeitadas.

$\frac{1350}{1600}=0,84(2)$

Performance: Entendendo que, durante esse turno, devido à quebra, a velocidade desse equipamento foi reduzida. Sua velocidade padrão é de 1.500 golpes por minuto e, foi reduzida para 1.000 golpes por minuto.

$\frac{1000}{1500}=0,67$

$O E E=$ produto das equações 1, 2 e $3 ; O E E=0,75 \times 0,84 \times 0,67$

Logo, diante deste exemplo, tem-se um índice de 0,4221 ou, 42,21\%.

\section{Metodologia de pesquisa}

Este trabalho trata de uma pesquisa de campo, com visitas in loco e coleta de dados, interações com especialistas e análise da situação e entendimento da causa, entendendo que esses fatores são fundamentais para estruturar a base da condução deste estudo. A estrutura lógica utilizada na condução deste artigo deu-se da seguinte forma: definição e entendimento da baixa performance do processo supracitado. Mediante ao entendimento desta definição, foi possível identificar métricas adequadas para avaliar a situação atual e, por meio de coleta de dados gerar conhecimento sobre o processo em questão e, com isso poder comparar o baseline em ações decorrentes deste objeto de estudo. Por meio de obtenção desses dados é possível gerar análises, 
inferências e fundamentar hipóteses com intuito de pontuar possíveis modificações no processo e entender a relação causa e efeito e quais são as variáveis vitais de maior impacto.

Diante de análises qualitativas e quantitativas, foi possível conhecer as ações adequadas que tal processo pudesse obter performance aceitáveis. O indicador de performance (OEE), para ser considerado como um índice de classe mundial, terá que performar acima dos 90\%. Para tabular os dados coletados, foi utilizado software estatístico Minitab, que em seguida, gerou quadros com estatísticas descritivas e gráficos. Na Figura 2, pode-se visualizar o fluxo metodológico utilizado nesta pesquisa.

Figura 2 - Fluxo metodológico

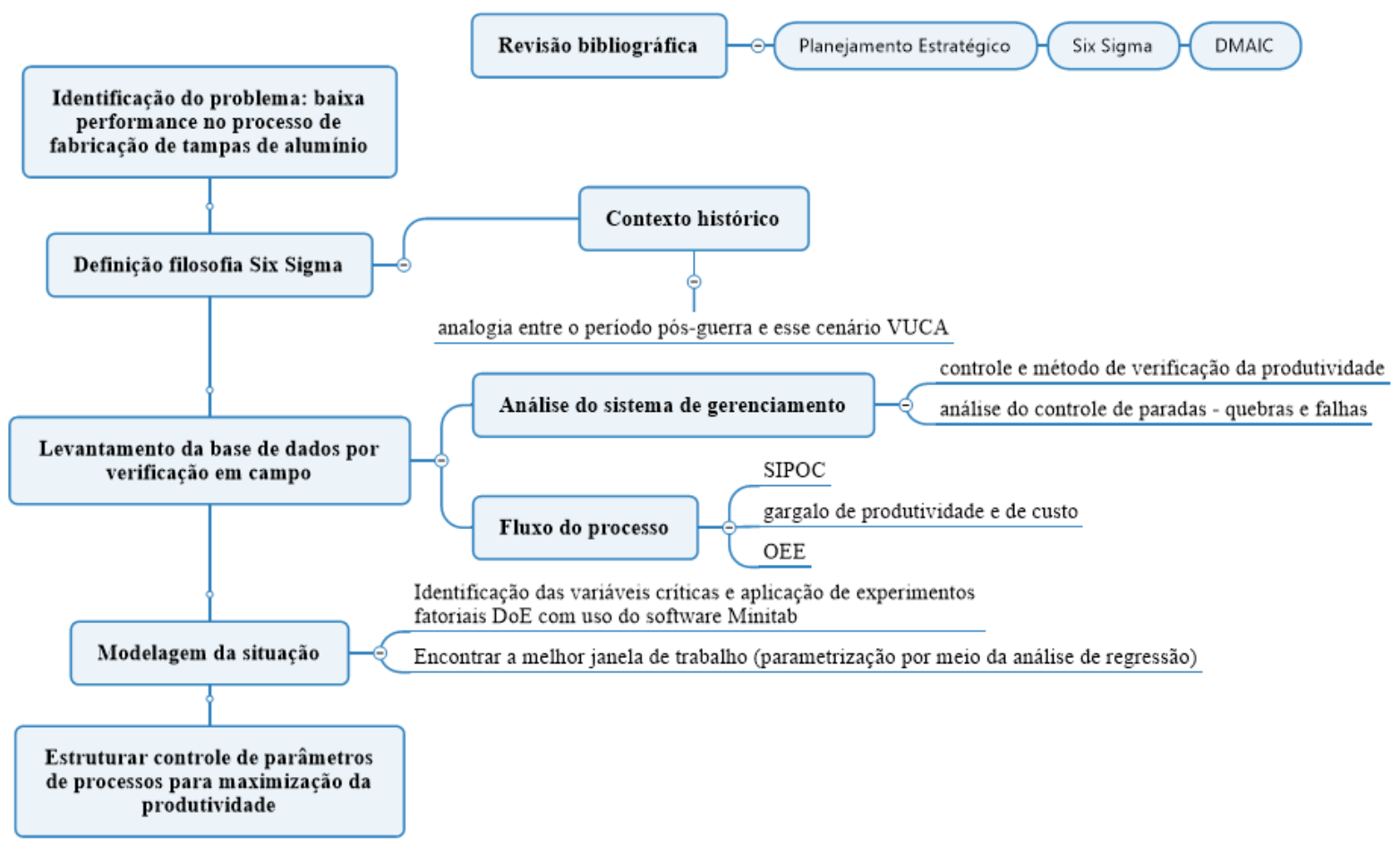

Fonte: Autoria própria (2021)

\section{Resultados e Discussão}

\subsection{Objeto de estudo}

Especificamente, o estudo se desenvolveu numa indústria global de embalagens de alumínio para bebidas, que fornece soluções em embalagens para bebidas. A implementação dessa metodologia se dará, na linha de fabricação de tampas de alumínio, de uma das unidades fabris, aqui no Brasil. A abordagem inicial é analisar os KPI's existentes, na operação, e medir a 
situação atual. Em seguida, criar um time de trabalho para servir de linha piloto e de laboratório da metodologia. O foco será aumentar a disponibilidade da linha de aplicação de selante.

ABRALATAS (2018) entende que o fluxo e as etapas de processo de fabricação de tampas, especificamente, são: fabricação da tampa básica, em seguida aplicação de selante (objeto de estudo) e, por fim a fabricação da tampa acabada. Na primeira etapa desse processo de fabricação, o termo atribuído à tampa básica é, por ser a conformação primária desse elemento, que por meio da conformação chapa de alumínio por meio de prensa hidráulica. Por fim, é formada a reborda, numa etapa em que são moldadas às partes da tampa que irão garantir sua recravação, ou seja, sua fixação à lata, conforme ilustra a Figura 3.

Figura 3 - Fluxograma do processo de fabricação de tampas ABRALATAS (2018)

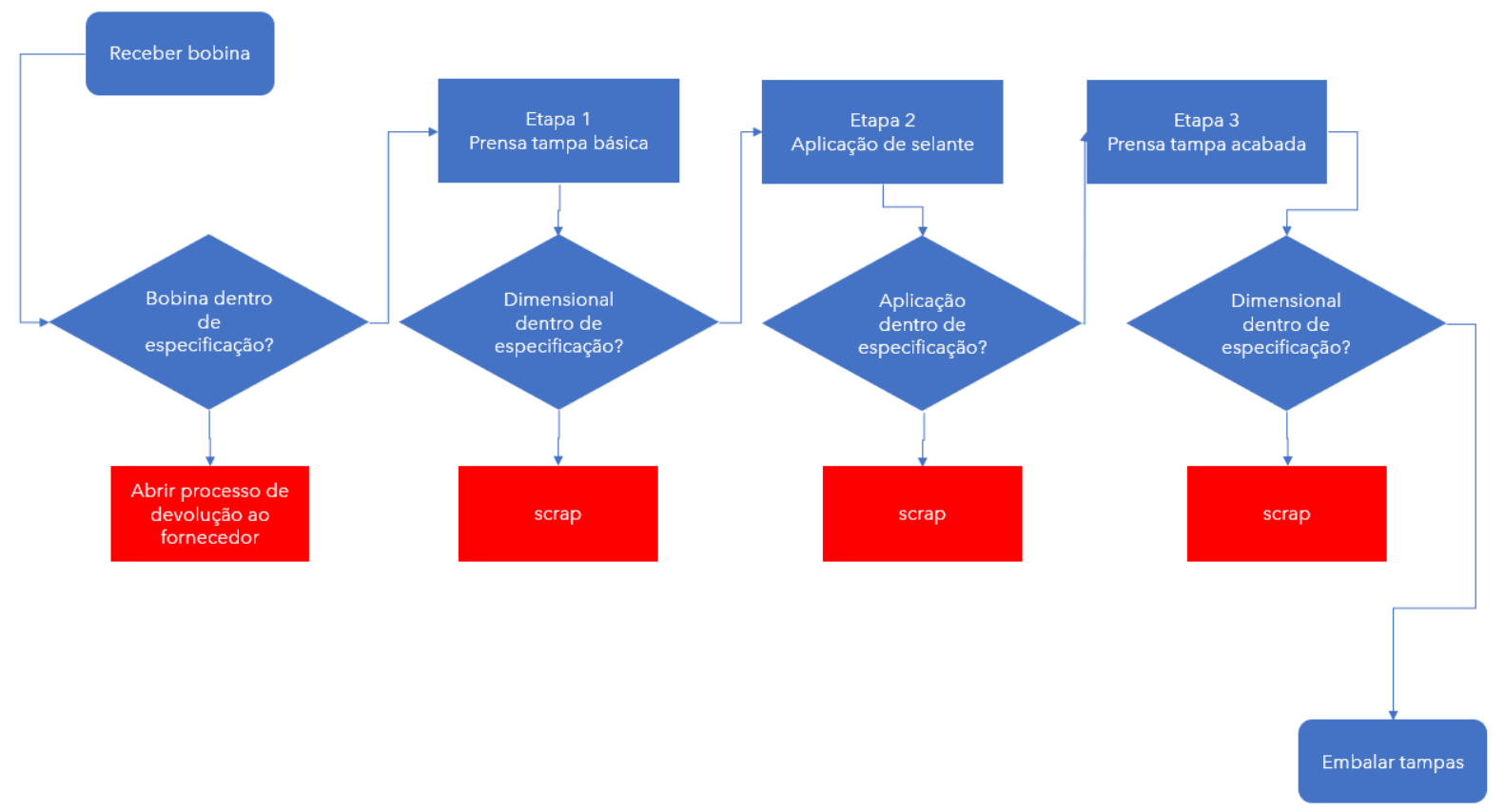

Fonte: Autoria própria (2021)

O processo de aplicação de selante, conforme a etapa 2 do fluxograma acima, componente responsável em garantir a hermeticidade entre a tampa e a lata. Inicialmente, foi identificado que a performance da linha de aplicação de selante frequentemente era considerada um gargalo de produção (termo utilizado para expressar alguma restrição). Werkema (2014) aponta para a importância da aplicação das ferramentas de qualidade, no processo de melhoria de um processo. Que neste caso, especificamente foi utilizado o fluxograma. Na busca de encontrar a causa raiz, foi realizado o desdobramento das análises afim de entender as componentes que interferem na baixa performance ao longo desse processo. A abordagem inicial, foi a aplicação 
do conceito de mapeamento de processos SIPOC (ferramenta de mapeamento de processos), ilustrada no diagrama abaixo, visto que, comprovadamente a área do processo mais frágil, de acordo com a teoria das restrições, seria a linha de aplicação de selante.

Figura 4 - Diagrama SIPOC

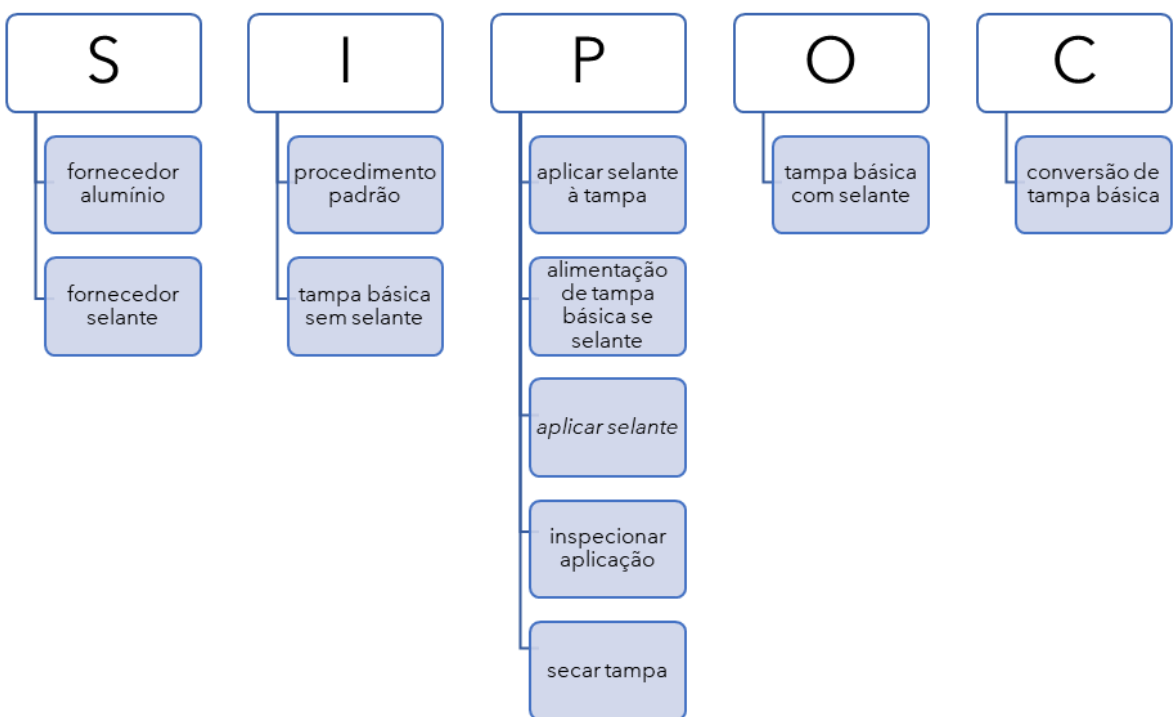

Fonte: Autoria própria (2021)

Esse estudo, se deu para analisar a performance inicial dessa linha gargalo e conhecer o baseline (linha de referência). Esse baseline $\left(H_{0}\right)$, conforme Figura 5, servirá de base comparativa durante a implementação das fases e passos DMAIC bem como, evidenciar a necessidade de mudar de patamar de performance. Já que a performance atual, apresentam constantes inconsistências, ao longo do tempo, comparado à meta estabelecida para esse processo. Para tal constatação, aplicou-se o teste de hipótese (teste t para uma amostra), comparando com um valor preestabelecido (meta OEE 82\%), onde verificou-se que o valor estabelecido está fora do intervalo de confiança da amostra analisada. Ou seja, o rendimento médio deste processo está abaixo da meta estabelecida. 
Figura 5 - Teste de hipótese - performance atual x meta $\mathrm{H}_{0}$

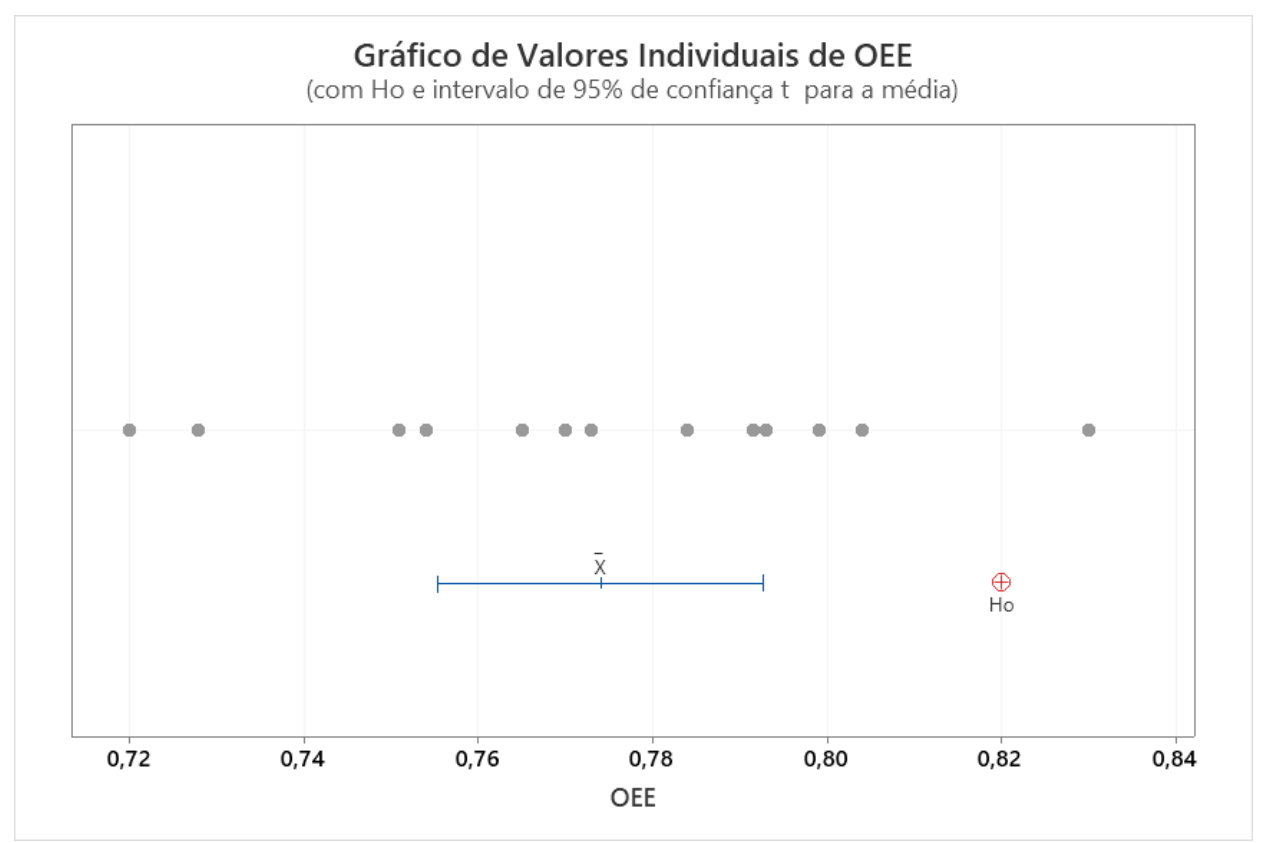

Fonte: Autoria própria (2021)

Entendendo que os vetores de composição do indicador de performance $(O E E)$, são disponibilidade, qualidade e performance, foi possível identificar a oportunidade de desdobrar a metodologia e seguir com as análises dos motivos da baixa performance e, entender quais fatores contribuem para perda desse indicador. E, após análise histórica dos motivos de paradas, foi possível chegar à seguinte conclusão: a ênfase do estudo, deverá ser o sistema de aplicação de selante, conforme mostra o gráfico abaixo, Figura 6.

Figura 6 - Gráfico motivos de parada

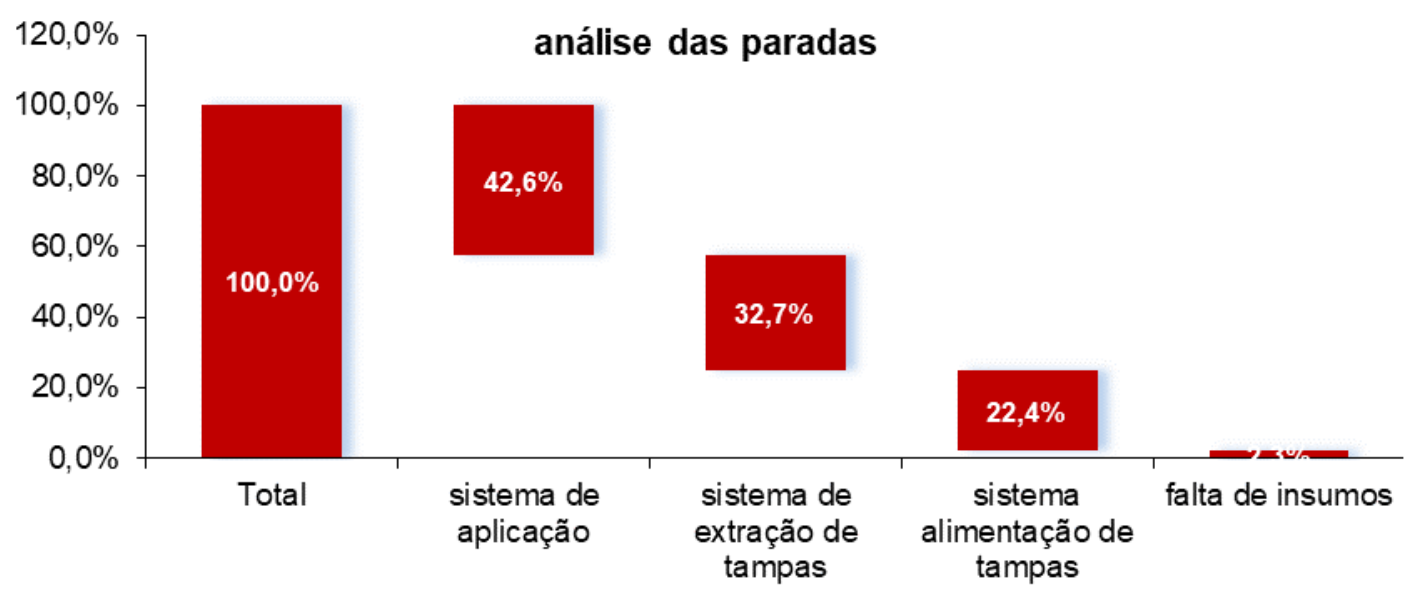

Fonte: Autoria própria (2021) 
Avaliando o impacto de cada causa, uma análise detalhada por subconjuntos (mapeamento detalhado de variáveis), conforme mostra o desdobramento abaixo, conforme Figura 7, com foco no sistema de aplicação, maior contribuição identificada, seguindo o princípio de Pareto.

Figura 7 - Análise do modo de falha - processo de aplicação

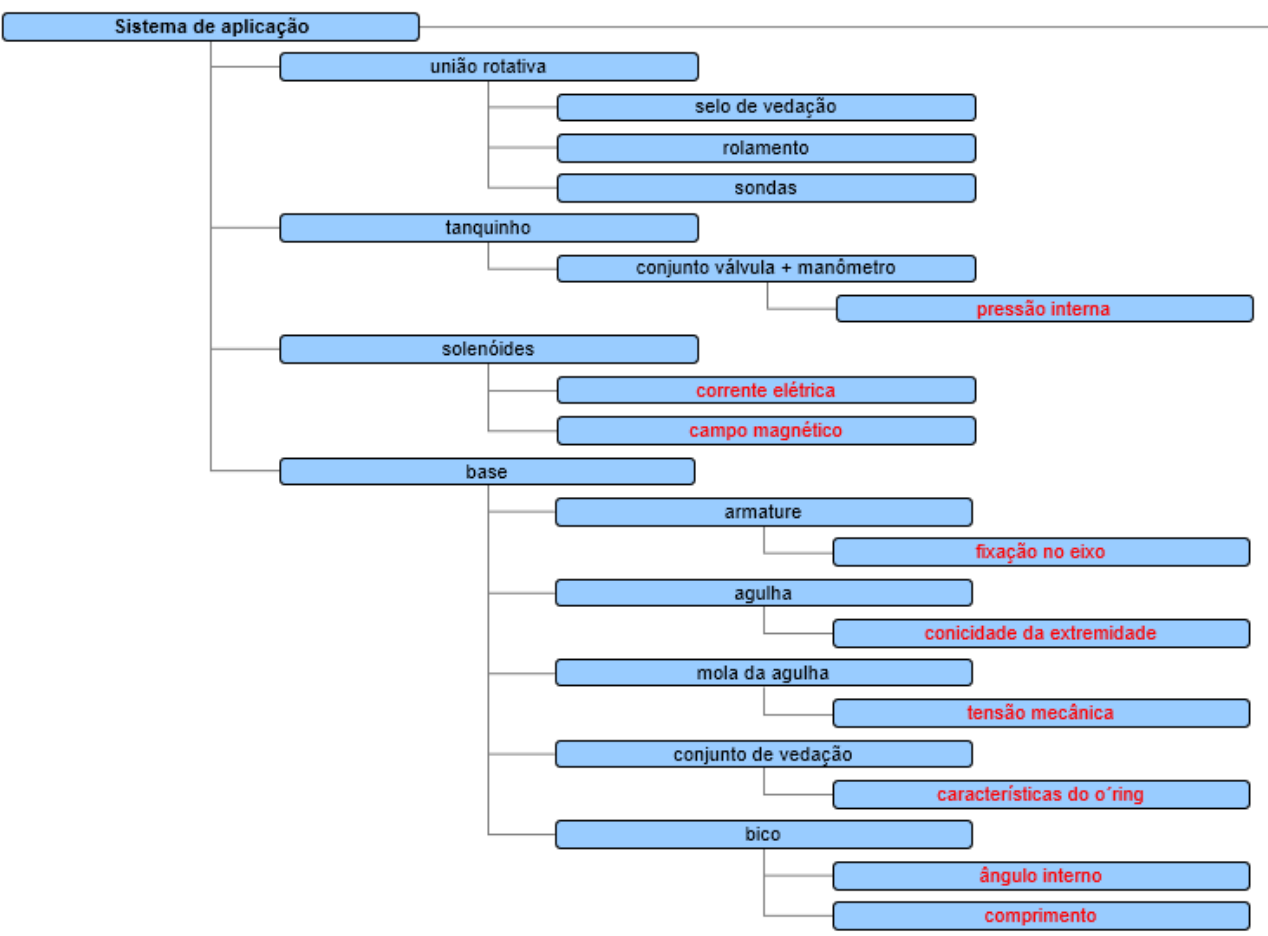

Fonte: Autoria própria (2021)

Rotondaro (2008), aborda a importância de identificar as variáveis críticas e a sua relação de causa e efeito. Considerando que o maior impacto no OEE é gerado pelo sistema de aplicação, se faz necessário ampliar o foco e detalhar tal sistema com o foco em aprofundar a busca pela causa raiz. Para isso, foi necessário estudar os componentes da aplicação, conforme Figura 7 , do conjunto de aplicação e, em detalhe o bico aplicador. Sua função é, aplicar o composto selante à tampa (material responsável em garantir a hermeticidade entre a tampa e a lata), através de comandos eletropneumáticos.

Rotondaro (2008), aborda a importância de identificar as variáveis críticas e a sua relação de causa e efeito. Considerando que o maior impacto no $O E E$ é gerado pelo sistema de aplicação, se faz necessário ampliar o foco e detalhar tal sistema com o foco em aprofundar a busca pela causa raiz. Para isso, foi necessário estudar os componentes da aplicação, conforme Figura 7, do conjunto de aplicação e, em detalhe o bico aplicador. Sua função é, aplicar o composto selante à tampa (material responsável em garantir a hermeticidade entre a tampa e a lata), através de comandos eletropneumáticos. 
Figura 8 - Desenho técnico do dispositivo de aplicação de selante

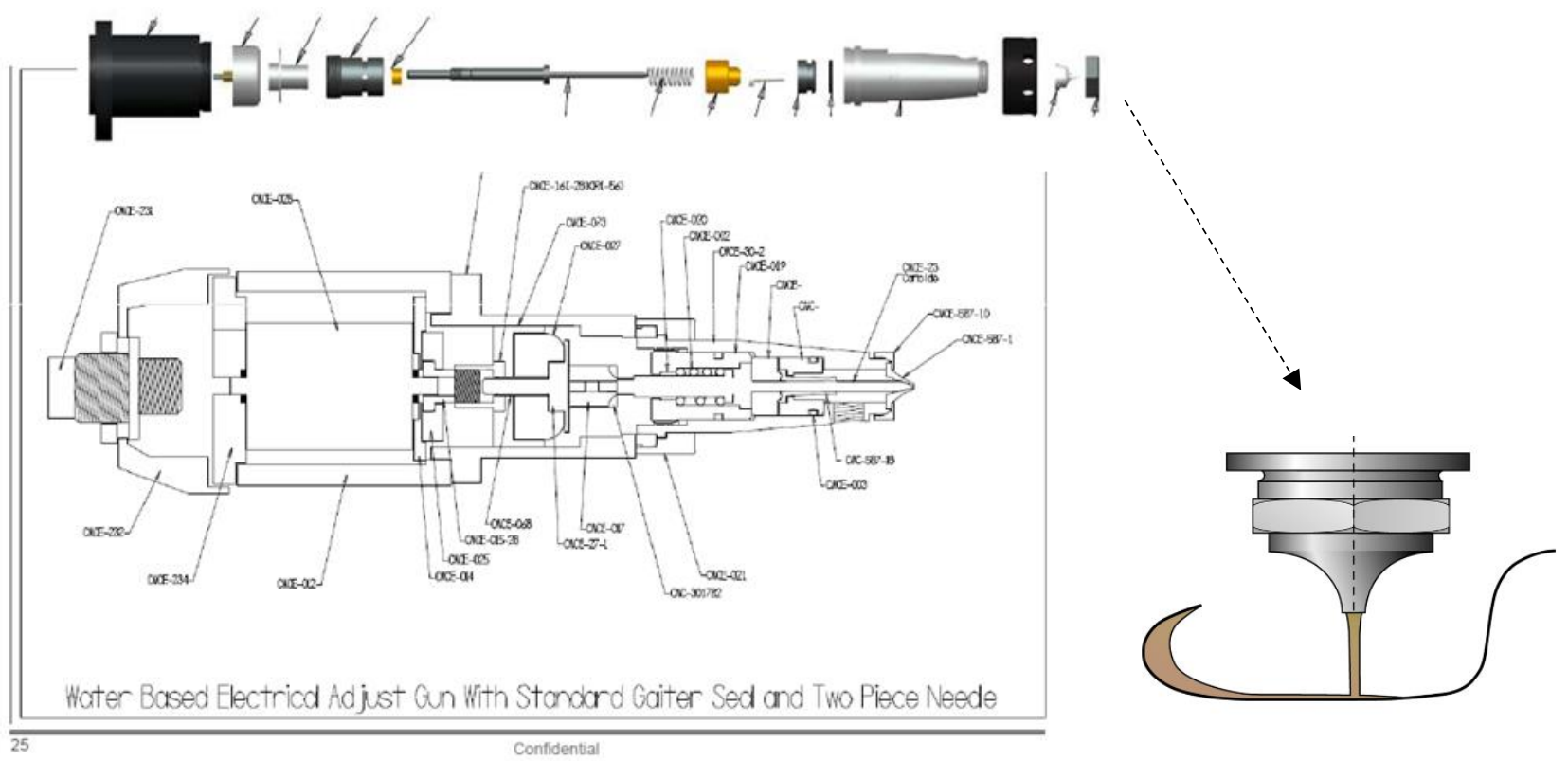

Fonte: Manual do fabricante do equipamento

Analisando, os fatores de cada componentes que influenciam na performance do equipamento, temos que a falha de aplicação é, uma somatória de interferências, geradas pelas variáveis: pressão de aplicação, velocidade de rotação da tampa e tempo de aplicação. Após identificar os fatores vitais desse processo, foi necessário criar um experimento fatorial $2^{3}$ ( 3 fatores com 2 níveis) para validação da hipótese, que resultou em um experimento com 8 saídas. Abaixo, detalhes do experimento ou saídas do DOE (Design of Experiment), onde é possível analisar a equação de regressão da performance do processo, em função das componentes de entradas desse processo (variáveis vitais do processo), utilizando o software estatístico Minitab.

\section{Full Factorial Design}

$\begin{array}{llll}\text { Factors: } & 3 & \text { Base Design: } & 3 ; \\ \text { Runs: } & 8 & \text { Replicates: } & 1 \\ \text { Blocks: } & 1 & \text { Center pts (total) : } & 0\end{array}$

Regression Equation in Uncoded Units

produção $=-1467938+389,3$ chuck speed +39749 time + 97795 pressão $-9,842$ chuck speed*time - 24,20 chuck speed*pressão - 2501 time*pressão + 0,6197 chuck speed*time*pressão

Entendendo que a aplicação do composto selante aplicado à tampa está sob interferência do fator "chuck speed” (rotação da tampa que faz a função de distribuição do selante à tampa, por meio da força centrífuga). O que é evidenciado no gráfico de efeitos principais, conforme 
Figura 9, onde a linha vermelha significa a relevância desse fator em relação ao grau de significância do teste estatístico.

Figura 9 - Gráfico de efeitos principais das variáveis vitais

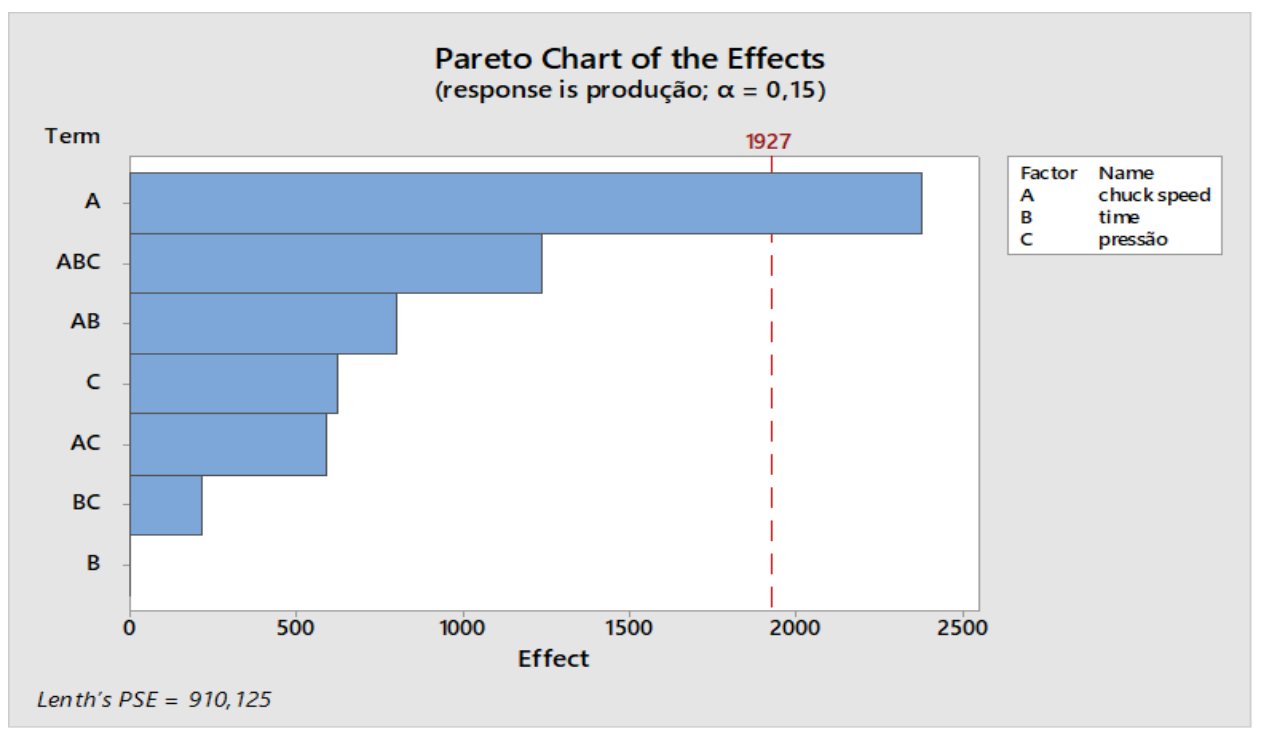

A variável de maior relevância, expressa pelo gráfico de Pareto das variáveis vitais (Figura 9), é a variável A (Chuck speed). E, conforme a Figura 10, temos a melhor configuração deste processo, em função do experimento, que são: rotação do chuck speed (4200 RPM), tempo de abertura da pistola de aplicação (42 ms) e pressão de aplicação (20 PSI). Diante da comprovação que não há interação entre as variáveis e que, a melhor configuração e combinação entre esses fatores analisados, chuck speed, time e pressão, estão descritos na Figura 10.

Abaixo, temos uma janela de processo com a melhor configuração parametrizada, em destaque no gráfico abaixo (cor vermelha). 
Figura 10 - Gráfico de análise do experimento fatorial

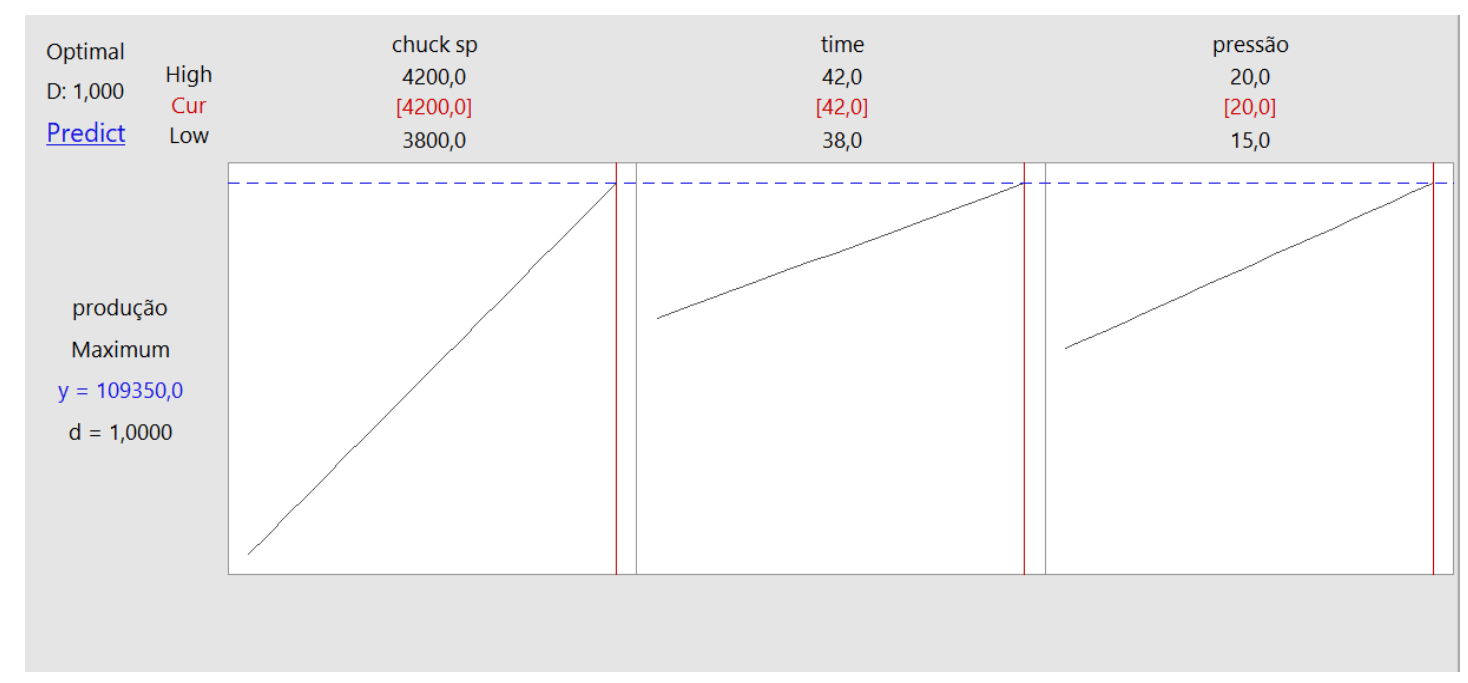

\section{Response Optimization: produção}

Parameters

$\begin{array}{llrlrrr}\text { Response } & \text { Goal } & \text { Lower } & \text { Target } & \text { Upper } & \text { Weight } & \text { Importance } \\ \text { produção } & \text { Maximum } & 104340 & 109350 & 1 & 1\end{array}$

Solution

$\begin{array}{llllrl}\text { Solution } & \begin{array}{l}\text { chuck } \\ \text { speed }\end{array} & \text { time } & \text { pressão } & \text { produção } & \text { Composite } \\ 1 & 4200 & 42 & 20 & 109350 & \text { Desirability } \\ 1 & & & & & 1\end{array}$

Multiple Response Prediction

Variable Setting

chuck speed 4200

time 42

pressão 20

\subsection{Parametrização para melhoria contínua}

Após identificação da variável de maior impacto, ou $X$ vermelho, foi possível evidenciar, por meio de um experimento fatorial, que é possível seguir com o projeto de melhoria, com os parâmetros encontrados nesse estudo. 
Figura 11 - Gráfico do efeito das médias

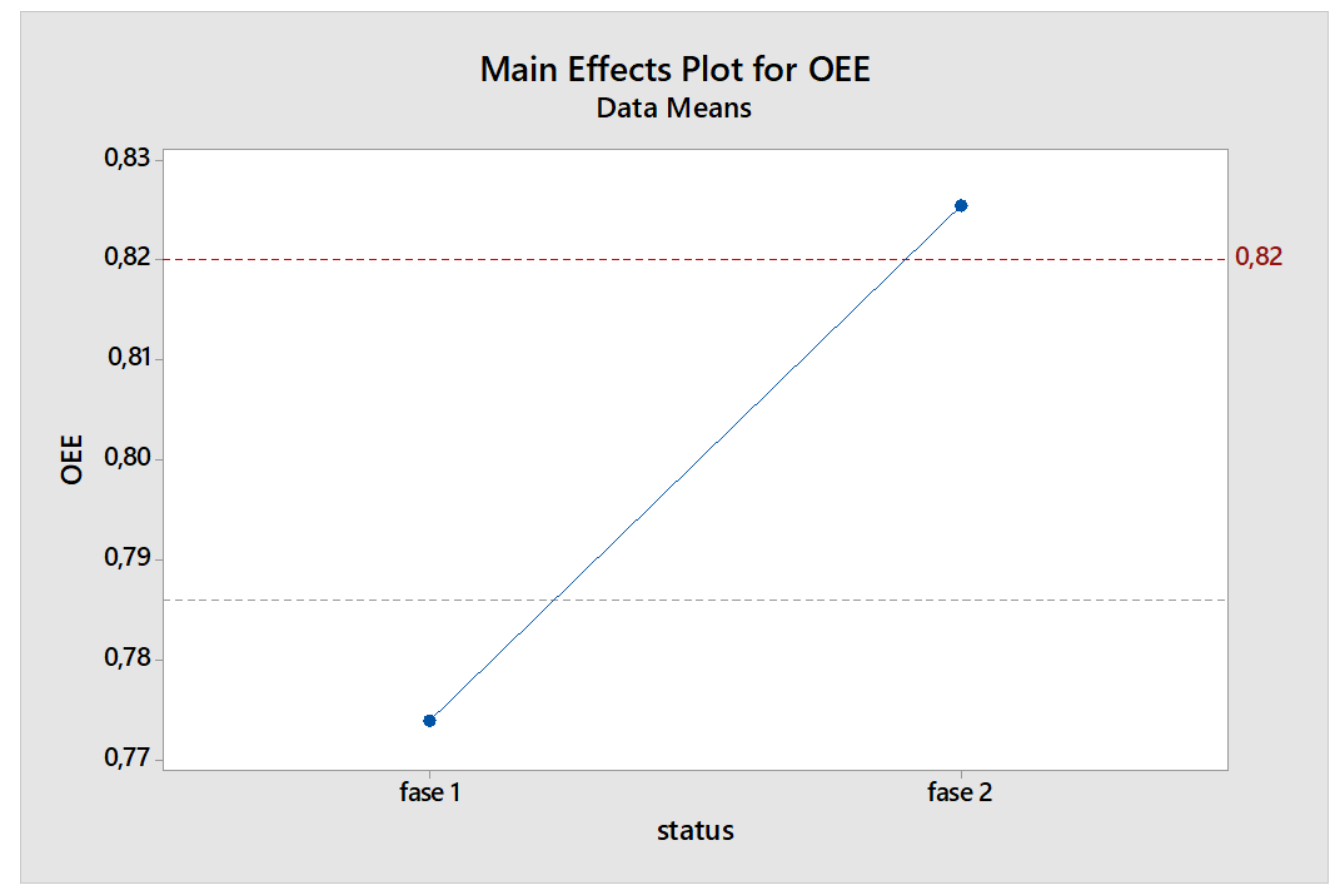

É possível visualizar que há diferença expressiva nas médias de OEE entre as fases 1 e 2 (performance antes x performance depois a implementação). Pode-se notar, de acordo com a Figura 11, que existe diferença significativa nas médias de OEE, entre essas fases (considerar valor do eixo vertical do gráfico X 100 e realizar leitura em \%). No gráfico de boxplot, destacado na Figura 12, é possível analisar a consistência na performance, após nova parametrização das variáveis. Nele pode-se validar a menor variabilidade (maior consistência) e maior mediana na fase 2, demonstrando maior performance. 
Figura 12 - Gráfico de boxplot - Performance do processo
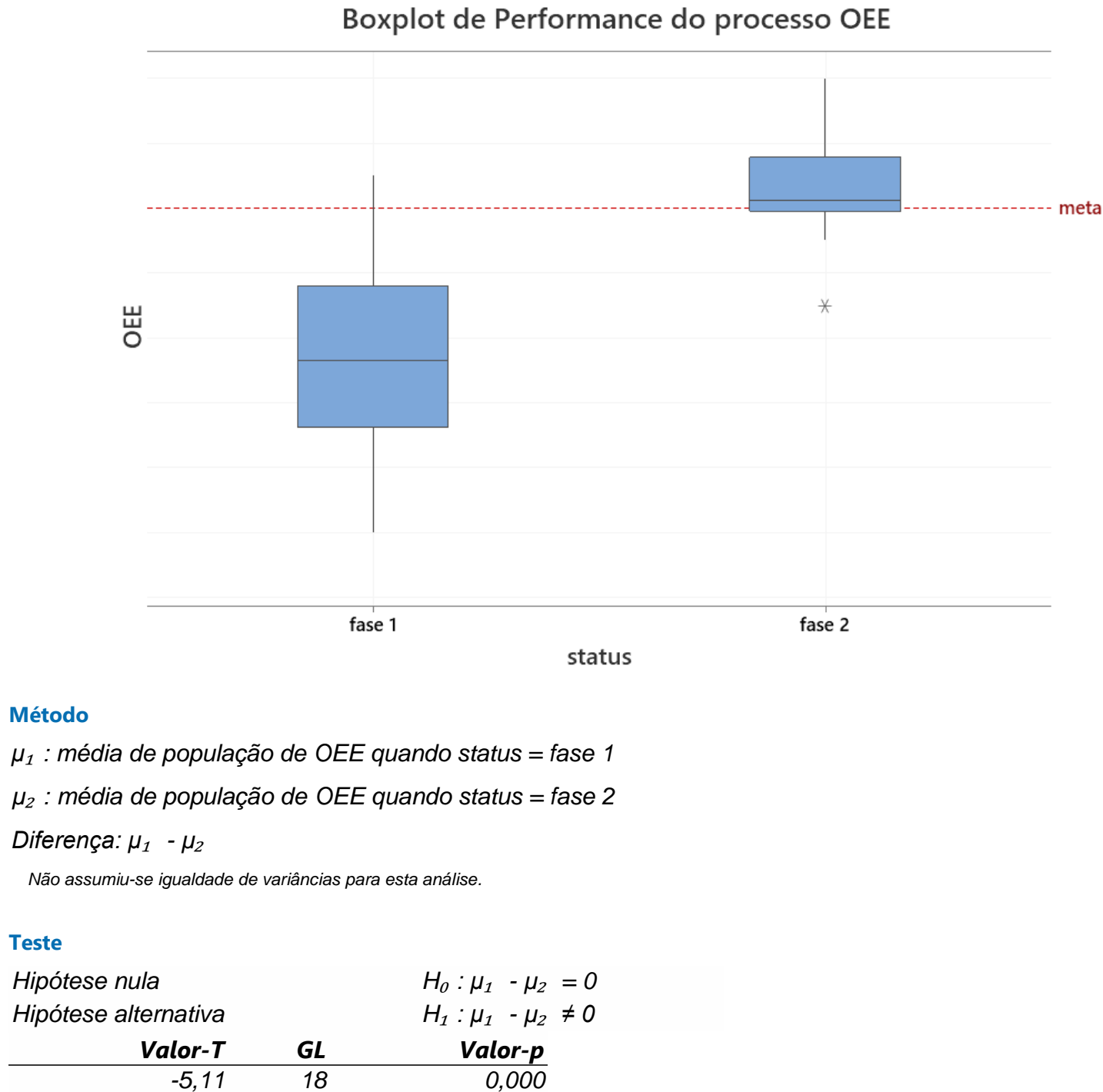

Aplicando o conceito de teste de hipótese, tem-se: a hipótese nula $\left(H_{0}\right)$, afirma-se que as médias de produção entre as fases 1 e fase 2 são iguais. E, a hipótese alternativa $\left(H_{a}\right)$, que as médias de produção entre a fase 1 e fase 2 são diferentes. Conforme observa-se o valor da estatística $P$ (Pvalue), 0,000 ou seja, menor que o nível de significância, 5\% (0,05), a hipótese nula deverá ser descartada. Isso significa dizer há diferença significativa entre as médias de produção testadas entre as fases 1 e 2 e que a hipótese alternativa será aceita. A observação do outlier (*) destacado na fase 2, pode ser interpretada como, em um dos meses do período em análise, o equipamento ficou indisponível após procedimento de manutenção.

Notação:

$H_{0}: \mu$ fase $1=\mu$ fase 2 
$H_{\mathrm{a}}: \mu$ fase $1 \neq \mu$ fase 2

Pvalue $<\alpha$ rejeita-se $H_{0}$

Pvalue $\geq \alpha$ não rejeita-se $H_{0}$

Onde $\alpha$ é o nível de significância, aplicado $5 \%(0,05)$.

Para validar que houve diferença significativa, no índice de performance, deste processo, após a etapa de análises, aplicou-se o teste de hipótese para inferir se houve mudança no comportamento da base de dados, após implementação das ações e redesenho da nova janela de processos. Evidenciando que a meta estabelecida, agora faz parte do intervalo de confiança do índice de performance, OEE. Dessa forma, pode-se inferir que houve mudança significativa no processo em análise, conforme demonstrado na Figura 13.

Figura 13 - Teste de hipótese - performance após ações x meta OEE

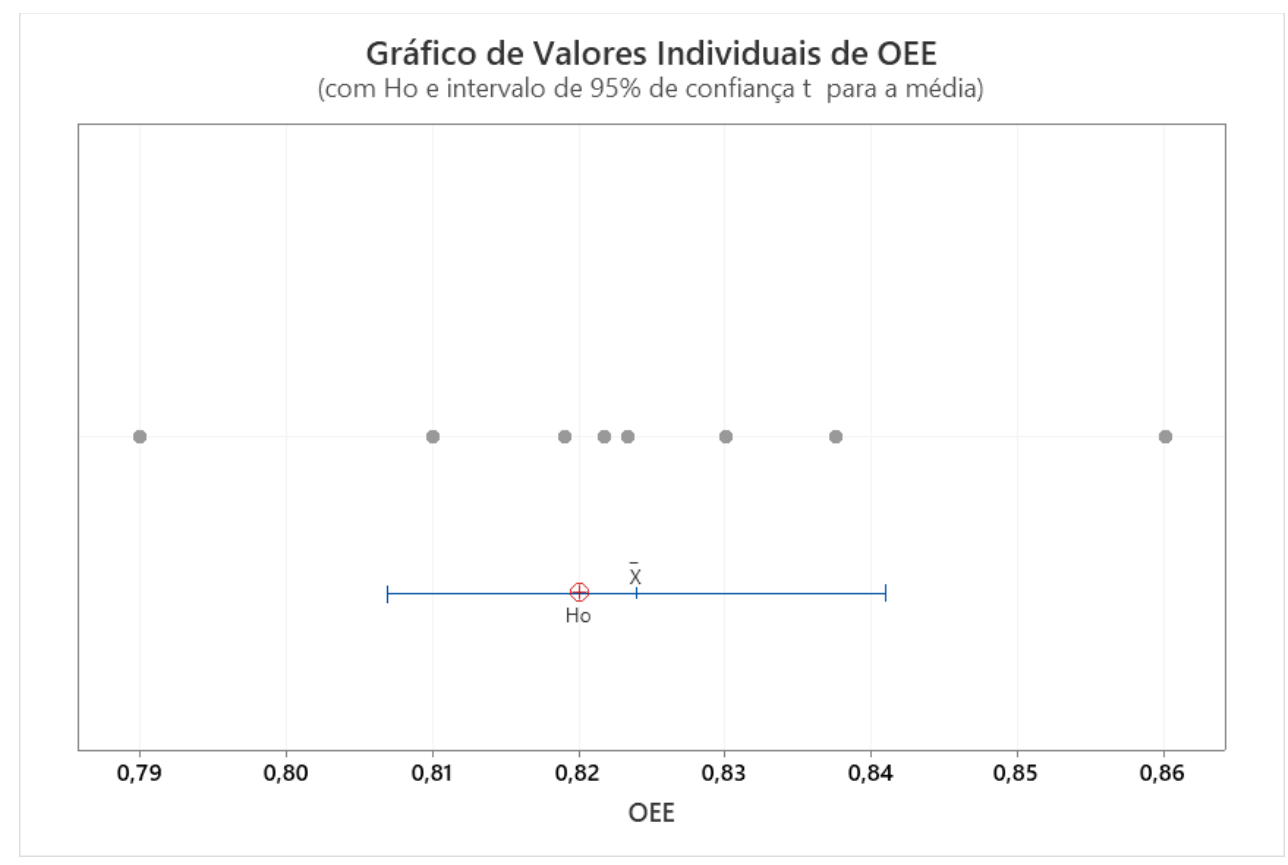

\section{Considerações Finais}

Muitas corporações apresentam baixa performance por interferência de variáveis e causas desconhecidas. A proposta fundamental desse trabalho é incorporar, na dinâmica corporativa, elementos concretos de melhoria de performance, contextualizando abordagens técnicas e científicas, diante do resultado exposto, aplicando o conceito de teste de hipótese para comparar duas amostras (fase 1 e fase 2), observou-se que a fase 2 é maior que a fase 1 . Dessa forma, 
validou-se que as duas amostras apresentam intervalos de confiança distintos, conforme evidenciado no gráfico abaixo, Figura14. Diante do exposto, é viável planejar um teste de escala industrial, replicando os parâmetros deste experimento. Em seguida, diante do resultado, padronizar tais parâmetros, visto que todas as variáveis desse processo foram mapeadas, identificadas e isoladas. Por fim, é necessário atualizar os procedimentos e instruções de trabalho, treinar as pessoas envolvidas nessa atividade para, em seguida desenvolver/revisar o plano de controle do novo processo.

Figura 14 - Teste de hipótese - Gráfico performance da linha

Teste t para 2 amostras para OEE por status

Relatório Resumo

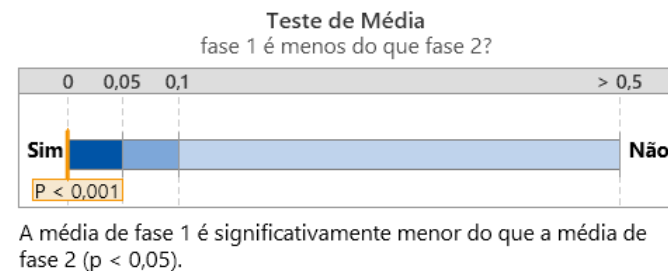

\begin{tabular}{lrr} 
& Amostras Individuais \\
Estatísticas & fase 1 & fase 2 \\
\hline Tamanho amostral & 13 & 4 \\
Média & 0,77404 & 0,82537 \\
$\quad$ Limite superior de 95\% & 0,7893 & 0,83511 \\
Desvio padrão & 0,030940 & 0,0082758
\end{tabular}

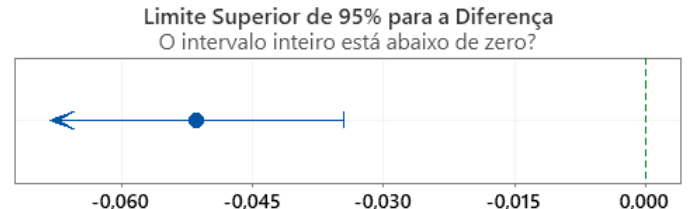

$\begin{array}{ll} & \text { Diferença Entre Amostras } \\ \text { Estatísticas } & \text { *Diferença }\end{array}$

$\begin{array}{lr}\text { Limite superior de } 95 \% & -0,051337 \\ & -0,034557\end{array}$

*Diferença $=$ fase 1 - fase 2

Comentários

- Teste: você pode concluir que a média de fase 1 é menor do que fase 2 no nível de significância de 0,05

- IC: quantifica a incerteza associada à estimativa da diferença nas médias dos dados amostrais. Você pode ter $95 \%$ de confiança de que a verdadeira diferença é menor que -0,034557.

- Distribuição dos Dados: compare a localização e as médias das

Distribuição de Dados Compare os dados e as médias das amostras.

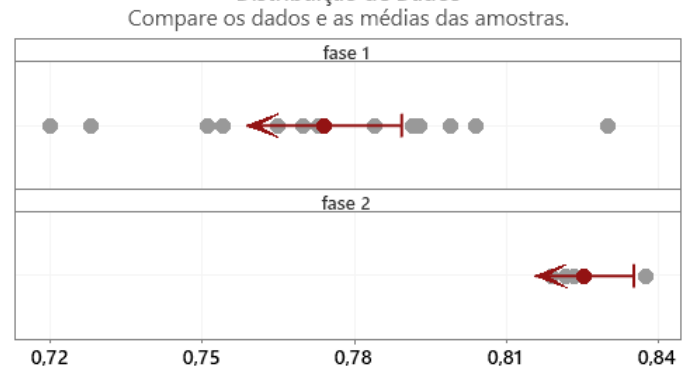
teste.

\section{REFERÊNCIAS}

ABRALATAS - Associação Brasileira dos Fabricantes de Latas de Alumínio. Site. Processo de fabricação da lata de alumínio para bebidas. 2019. Disponível em: 〈http://www.abralatas.org.br/\#containerLata〉. Acesso em: 16 mai. 2020 .

BORNIA, A. C. Engenharia de custos. Apostila da UFSC. Curso de Mestrado. 1997. Mensuração das perdas dos processos produtivos: uma abordagem metodológica de controle interno. Florianópolis. 1995 Tese (Doutorado em Engenharia de Produção), PPGEP, UFSC. 
DENNIS, PASCAL, Produção Lean Simplificada: um Guia para entender o sistema de produção mais poderoso do mundo. 2 Ed. Porto Alegre. Bookman editora, 2008.

HARRY D.; SCHROEDER, R. Six Sigma: the breakthrough management strategy revolutionizing the Worlds Top Corporation. New York: Doubleday, 2000.

KOTLER, P. KELLER, K. L. Administração de marketing. 12. Ed. São Paulo: Pearson Hall, 2006.

PYZDEK, T; KELLER, P. Seis Sigma: guia do profissional, um guia completo para Green Belts, Black Belts e Gerentes em todos os níveis. 3 ed. Rio de Janeiro. Alta Books, 2011.

ROTONDARO, R. G. Seis Sigma: estratégia gerencial para a melhoria de processos, produtos e serviços. São Paulo: Atlas, 2008.

SANTOS, A. C. S. G.; RIBEIRO, I. M.; SALVE, A. S.; MITIE JI, C., FERREIRA, L. A. F., \& HORA, H. R. M. Indicador OEE e ferramentas da qualidade: uma aplicação integrada no processo de destilação de uma indústria de biotecnologia. São Paulo, Revista Exacta v. 17, n. 2, p. 165-184. abr./jun. 2019.

SIMÃO, S. P. Implantação do indicador OEE (overall equipment effectiveness) em uma fábrica de autopeças. 2017. 50 f. Trabalho de conclusão de curso bacharelado em engenharia mecânica - Faculdade de Engenharia de Guaratinguetá, 2017. Disponível em: 〈http://hdl.handle.net/11449/157009〉.

STAMATIS, H. DEAN, Six Sigma Fundamentals: A complete guide to the system, methods and tools. New York, Productivity Press, 2004.

WERKEMA, M. C. C. As ferramentas da qualidade no gerenciamento de processos. 4 ed. Belo Horizonte: QFCO. 1995.

WERKEMA, M. C. C. Criando a cultura Seis Sigma. Nova Lima: Werkema, 2004. 